\title{
Assessing Vasculitis in Giant Cell Arteritis by Ultrasound: Results of OMERACT Patient-based Reliability Exercises
}

\author{
Valentin S. Schäfer ${ }^{(D)}$, Stavros Chrysidis, Christian Dejaco, Christina Duftner, \\ Annamaria Iagnocco, George A. Bruyn, Greta Carrara, Maria Antonietta D’Agostino, \\ Eugenio De Miguel, Andreas P. Diamantopoulos, Ulrich Fredberg, Wolfgang Hartung, \\ Alojzija Hocevar, Aaron Juche, Tanaz A. Kermani, Matthew J. Koster, Tove Lorenzen, \\ Pierluigi Macchioni, Marcin Milchert, Uffe Møller Døhn, Chetan Mukhtyar, Cristina Ponte, \\ Sofia Ramiro, Carlo A. Scirè, Lene Terslev, Kenneth J. Warrington, Bhaskar Dasgupta, \\ and Wolfgang A. Schmidt
}

\begin{abstract}
Objective. To test the reliability of Outcome Measures in Rheumatology Clinical Trials (OMERACT) consensus-based ultrasound definitions for normal and vasculitic temporal and axillary arteries in patients with giant cell arteritis (GCA) and in controls.

Methods. A preliminary 1-day meeting and a full 3-day meeting fulfilling OMERACT Ultrasound Group guidelines were held. Temporal and axillary arteries were examined at 2 timepoints by 12 sonographers on 4 patients with GCA and 2 controls. The aim was to test inter- and intrareader reliability for normal findings, halo sign, and compression sign. In both meetings, patients had established GCA. Pathology was more recent in the full meeting, which was preceded by $6 \mathrm{~h}$ of training. Scanning time was 15-20 min instead of 10-13 min.

Results. In the preliminary exercise, interreader reliabilities were fair to moderate for the overall diagnosis of GCA (Light $\kappa$ 0.29-0.51), and poor to fair for identifying vasculitis in the respective anatomical segments (Light $\kappa$ 0.02-0.46). Intrareader reliabilities were moderate (Cohen $\kappa 0.32-0.64$ ). In the main exercise, interreader reliability was good to excellent (Light $\kappa$ 0.76-0.86) for the overall diagnosis of GCA, and moderate to good (Light $\kappa$ 0.46-0.71) for identifying vasculitis in the respective anatomical segments. Intrareader reliability was excellent for diagnosis of GCA (Cohen $\kappa$ $0.91)$ and good (Cohen $\kappa ~ 0.71-0.80)$ for the anatomical segments.

Conclusion. OMERACT-derived definitions of halo and compression signs of temporal and axillary arteries are reliable in recent-onset GCA if experienced sonographers ( $>300$ examinations) have 15-20 min for a standardized examination with prior training and apply $>15 \mathrm{MHz}$ probes . (First Release July 1 2018; J Rheumatol 2018;45:1289-95; doi:10.3899/jrheum.171428)
\end{abstract}

Key Indexing Terms:

GIANT CELL ARTERITIS ULTRASOUND RELIABILITY DIAGNOSIS VASCULITIS

From the University Hospital Bonn III, Medical Clinic, Department of Oncology, Hematology and Rheumatology, Bonn; Immanuel Krankenhaus Berlin, Medical Center for Rheumatology Berlin-Buch, Berlin; Asklepios Medical Center, Bad Abbach, Germany; Hospital of Southwest Denmark, Esbjerg; Diagnostic Centre Region Hospital Silkeborg, Silkeborg; Odense University Hospital, Odense; Copenhagen Center for Arthritis Research (COPECARE), Glostrup, Denmark; Medical University Graz, Graz;

Medical University Innsbruck, Innsbruck, Austria; Hospital of Bruneck, Bruneck; Università degli Studi di Torino, Turin; Epidemiology UnitItalian Society for Rheumatology (SIR), Milan; Arcispedale Santa Maria Nuova, Reggio Emilia; University of Ferrara, Italy; MC Groep Hospitals, Lelystad; Leiden University Medical Center, the Netherlands; Hôpital Ambroise Paré, Boulogne-Billancourt, France; University Hospital La Paz, Madrid, Spain; Martina Hansens Hospital, Barum, Oslo, Norway; University Medical Centre Ljubljana, Ljubljana, Slovenia; University of California at Los Angeles, Los Angeles, California; Mayo Clinic,

Rochester, Minnesota, USA; Pomeranian Medical University, Szczecin,

Poland; Norfolk and Norwich University Hospital, Norwich; Southend

University Hospital, UK National Health Service (NHS) Foundation Trust and Anglia Ruskin University, Westcliff, UK; Rheumatology Research Unit, Instituto de Medicina Molecular, Faculty of Medicine, University of Lisbon; Rheumatology Department, Hospital de Santa Maria - CHLN, Lisbon, Portugal.

The preliminary exercise was funded in connection with the International Symposium on Giant Cell Arteritis, Polymyalgia Rheumatica and Large Vessel Vasculitis in Southend, United Kingdom. The full exercise was funded by a grant from Roche Pharma Germany. Ultrasound equipment was provided for both exercises by Esaote SpA, Genoa, Italy. V.S. Schäfer, MD, University Hospital Bonn III, Medical Clinic, Department of Oncology, Hematology and Rheumatology, and Immanuel Krankenhaus Berlin, Medical Center for Rheumatology Berlin-Buch; S. Chrysidis, MD, Hospital of Southwest Denmark; C. Dejaco, MD, PhD, Medical University Graz, and Hospital of Bruneck; C. Duftner, MD, PhD, Medical University Innsbruck; A. Iagnocco, MD, Università degli Studi di Torino; G.A. Bruyn, MD, PhD, MC Groep Hospitals; G. Carrara, MSc, Epidemiology Unit-SIR; M.A.D'Agostino, MD, PhD, Hôpital Ambroise Paré; E. De Miguel, MD, University Hospital La Paz;

A.P. Diamantopoulos, MD, PhD, MPH, Martina Hansens Hospital;

Personal non-commercial use only. The Journal of Rheumatology Copyright $\odot$ 2018. All rights reserved 
Early and accurate diagnosis of giant cell arteritis (GCA) is imperative. Failure to accurately diagnose and expeditiously treat GCA may lead to vision loss and other severe ischemic complications, whereas misdiagnosis of non-GCA pathology as GCA leads to inappropriate glucocorticoid use and toxicity. Temporal artery biopsy (TAB) has been the diagnostic test of choice. However, TAB is invasive, and results are not immediately available. Hence it is increasingly being replaced by imaging, which includes ultrasound (US), magnetic resonance imaging (MRI), computed tomography (CT), and 18F-fluorodeoxyglucose positron emission tomography (FDG-PET) ${ }^{1}$. FDG-PET and CT facilitate the examination of extracranial arteries to confirm the diagnosis of large-vessel GCA and exclude alternative serious pathology. MRI and particularly US can additionally visualize temporal arteries and other superficial cranial arteries.

US is widely available in rheumatology practice. It is patient-friendly, reproducible, and repeatable. Modern US transducers achieve image resolution of $0.1 \mathrm{~mm}$ for superficial arteries, which is higher than that of other imaging techniques ${ }^{1}$. US displays a noncompressible, hypoechoic, most commonly concentric arterial wall thickening ("halo sign") in acute $\mathrm{GCA}^{2,3}$. Alongside medical history and clinical examination it can be used in fast-track clinics offering appointments for patients within $24 \mathrm{~h}$, to rapidly confirm or exclude the diagnosis of suspected GCA. Two studies have shown a decrease of permanent irreversible vision loss after inauguration of fast-track clinics ${ }^{4,5}$.

US in all patients with suspected GCA is cost-effective compared to biopsy plus clinical judgment without imaging ${ }^{6}$. It has a higher sensitivity than TAB regarding the clinical diagnosis, particularly in patients with large-vessel GCA ${ }^{6,7}$. Several studies have investigated the accuracy, and construct and criterion validity of US in the diagnosis of GCA,

U. Fredberg, MD, PhD, Diagnostic Centre Region Hospital Silkeborg, and Odense University Hospital; W. Hartung, MD, Asklepios Medical Center; A. Hocevar, MD, MSc, University Medical Centre Ljubljana; A. Juche, MD, Immanuel Krankenhaus Berlin, Medical Center for Rheumatology Berlin-Buch; T.A. Kermani, MD, University of California at Los Angeles; M.J. Koster, MD, Mayo Clinic; T. Lorenzen, MD, Diagnostic Centre Region Hospital Silkeborg; P. Macchioni, MD, Arcispedale Santa Maria Nuova; M. Milchert, MD, PhD, Pomeranian Medical University; U.M.D $\phi h n, M D, P h D, C O P E C A R E ; C . M u k h t y a r, M B B S, M S c, M D$, Norfolk and Norwich University Hospital; C. Ponte, MD, Rheumatology Research Unit, Instituto de Medicina Molecular, Faculty of Medicine, University of Lisbon, and Rheumatology Department, Hospital de Santa Maria-CHLN; S. Ramiro, MD, MSc, PhD, Leiden University Medical Center; C.A. Scirè, $M D, P h D$, Epidemiology Unit - SIR, and University of Ferrara; L. Terslev, MD, PhD, COPECARE; K.J. Warrington, MD, Mayo Clinic; B. Dasgupta, MBBS, MD, FRCP, Southend University Hospital, NHS Foundation Trust and Anglia Ruskin University; W.A. Schmidt, MD, Immanuel Krankenhaus Berlin, Medical Center for Rheumatology Berlin-Buch.

Address correspondence to Dr. V.S. Schäfer, University Hospital Bonn, Department of Rheumatology and Clinical Immunology, Medical Clinic and Policlinic III, Sigmund-Freud-Str. 25, Bonn 53105, Germany.

E-mail: valentin.s.schaefer@hotmail.de

Accepted for publication March 29, 2018. including 3 metaanalyses ${ }^{8,9,10}$. There is a trend to higher sensitivities in newer studies because of better technology and increasing experience. A new metaanalysis including studies until February 2017 revealed a pooled sensitivity of $77 \%$ and a pooled specificity of $96 \%$ with a positive likelihood ratio of 19 and a negative likelihood ratio of 0.2 for the halo sign in temporal arteries compared to the clinical diagnosis of $\mathrm{GCA}^{11}$.

Nevertheless, issues have been raised regarding the diagnostic performance and reliability of US, thus challenging its overall usefulness in GCA. A recent phase III trial enrolled $37 \%$ of its patients on the basis of crosssectional imaging, although US was not included ${ }^{12}$. Another phase III trial (ClinicalTrials.gov identifier: NCT02531633) included US as an eligible diagnostic modality. This trial was however prematurely terminated in October 2017 by the sponsor, based on the decision to discontinue development of sirukumab in autoimmune diseases. Recently published European League Against Rheumatism recommendations on imaging in large-vessel vasculitis suggest US as the first imaging modality particularly in patients with suspected predominantly cranial $\mathrm{GCA}^{13}$.

An Outcome Measures in Rheumatology Clinical Trials (OMERACT) US subgroup on large-vessel vasculitis was formed. A Delphi survey based on a systematic literature search arrived at US definitions for normal temporal and axillary arteries, the halo sign, and the "compression sign." These definitions were tested in a Web-based exercise on still images and videos of normal and vasculitic temporal and axillary arteries. The reliability was excellent, with interreader agreements of $91-99 \%$ and mean $\kappa$ values of $0.83-0.98$ for both interreader and intrareader reliability ${ }^{14}$.

The focus of our study, described herein, is the OMERACT validation process, which tested the inter- and intrareader reliability of the aforementioned definitions for both normal and vasculitic arteries. The real-time patientbased exercises required simultaneous data acquisition and interpretation.

\section{MATERIALS AND METHODS}

Study design and setting. A preliminary 1-day meeting was held following the International Symposium on Giant Cell Arteritis, Polymyalgia Rheumatica and Large Vessel Vasculitis in Southend, UK, in March 2016 to test the feasibility and study setting for a patient-based exercise. Lessons learned were implemented in a definitive 3-day exercise in Berlin, Germany, in February 2017, modeled on previous OMERACT Ultrasound Working Group studies for testing patient-based reliability of US in rheumatic diseases ${ }^{15,16,17}$. The methodology and reporting of the Berlin OMERACT reliability exercise adhered to the recommendations from the Enhancing the Quality and Transparency of Health Research network ${ }^{18}$ using the Guidelines for Reporting Reliability and Agreement Studies Statement ${ }^{19}$.

US examination. At each meeting, 12 sonographers individually examined 6 study subjects. All sonographers were previously involved in the development of the consensus-based US definitions. Each sonographer performed bilateral examinations of the common superficial temporal artery, its frontal and parietal branches and of the axillary arteries (i.e., 8 artery segments per patient) in longitudinal and transverse scans applying a binary score for

Personal non-commercial use only. The Journal of Rheumatology Copyright @ 2018 . All rights reserved. 
vasculitis US lesions as defined by OMERACT ${ }^{14}$. The subject was lying on an examination couch in supine position. The head was rotated slightly toward the examiner for examining the left temporal artery and away from the examiner for examining the right temporal artery. The probe was placed in the axilla for examining the axillary artery. After a predetermined time, sonographers rotated to the next station until every sonographer examined all patients/controls. The data were collected immediately after each examination to exclude communication between sonographers. Sonographers were blinded to the study subjects' diagnosis. They were not allowed to communicate with the patients about signs or symptoms of the disease. None of the examined patients had visibly swollen temporal arteries. An identical examination sequence was repeated later the same day to assess intrareader reliability.

US equipment and settings. Esaote MyLab Twice/Class systems equipped with 6-18 MHz linear array transducers were used in the exercises. In the Berlin meeting, 2 additional Esaote MyLab 8 machines were used. The following settings were applied for the examination of the temporal arteries (axillary arteries): B-mode frequency $18 \mathrm{MHz}(14 \mathrm{MHz})$, image depth 1.5 $\mathrm{cm}(3 \mathrm{~cm}), 1$ focus point at $0.5 \mathrm{~cm}(1.5 \mathrm{~cm})$ below skin surface, color Doppler frequency $9 \mathrm{MHz}(6 \mathrm{MHz})$, and pulse repetition frequency $2.5 \mathrm{KHz}$ (3.5 KHz). Sonographers were advised not to change these predefined settings except for adjusting image depth and focus point position for the examination of the axillary arteries, if necessary.

Preliminary meeting. The sonographers received no training on US machines and settings before the exercise. Thirteen minutes were allocated for scanning and scoring the findings for the first round and $10 \mathrm{~min}$ for the second round. The limit was set after a discussion about daily clinical practice conditions, where these time frames seemed to be adequate and realistic.

The examined study subjects were chosen by the convenors (BD, WAS), who did not participate in the reliability exercise. WAS, being unblinded to the history and diagnosis of all study subjects and having performed $>5000$ scans in suspected GCA over 23 years, examined all study subjects in addition to the other sonographers (independent sonographer) to decide whether arterial segments were exhibiting clear or ambivalent pathology and to store reference images and videos. The examined study subjects were 63-76 years old (mean age 68 yrs). Four of them were females. Four study subjects had GCA consistent with the revised inclusion criteria of the SIRRESTA trial (NCT02531633). These criteria require age $\geq 50$ years, erythrocyte sedimentation rate $50 \geq \mathrm{mm} / \mathrm{h}$, and/or C-reactive protein $\geq 2.45$ $\mathrm{mg} / \mathrm{dl}(24.5 \mathrm{mg} / \mathrm{l})$, unequivocal cranial symptoms of GCA and/or polymyalgia rheumatica, and evidence of large-vessel vasculitis by crosssectional imaging including US if diagnosis is not confirmed histologically. Further, the diagnosis had remained unchanged until the exercise. By the time of the exercise, patients were receiving glucocorticoids for 5 weeks, 2 years, 2 years, and 6 years. One of the 2 controls had an uncommon finding of arteriosclerosis of both axillary arteries.

All sonographers were rheumatologists except one who was in his last year of rheumatology training. Prior to the exercise, 7 sonographers had performed $>300$ scans of temporal and axillary arteries before, 2 had performed 101-300 scans, 2 had performed 51-100 scans, and 1 had performed $<20$ scans. Five sonographers used US machine types in their institutions similar in manufacturer and price level to the ones used in the exercise.

Full meeting. The meeting included $6 \mathrm{~h}$ of practical US training on healthy individuals and patients with GCA, different from those who participated in the exercise, using the machines and settings used in the exercise. In the exercise, $20 \mathrm{~min}$ were allocated for scanning and scoring the findings for the first round and $15 \mathrm{~min}$ for the second round.

The examined study subjects were chosen and also examined by the convenor (WAS), who did not participate in the reliability exercise. Subjects' age ranged from 56 to 80 years (mean 68 yrs). Four of them were females. Four study subjects had GCA fulfilling the above-mentioned inclusion criteria. They had been receiving glucocorticoids for 4,7 , and 8 months. The fourth patient had a persistent halo sign of temporal arteries for 4 years despite discontinuation of glucocorticoids. Two controls never had any signs or symptoms of GCA.

Eight of the 12 sonographers had participated in the preliminary exercise. All sonographers were rheumatologists. Eleven sonographers had performed $>300$ scans of temporal and axillary arteries before. Two of them had indicated an experience of 101-300 scans at the time of the preliminary meeting. One sonographer had performed 51-100 scans at the time of each meeting. Six sonographers used US machines in their institutions similar in manufacturer and price level to the ones used in the exercise.

Ethics committee approval was obtained from the Berlin Medical Association (Berliner Ärztekammer, Eth-04-17). All patients provided written informed consent prior to participation in our study.

Definitions. The definitions obtained by the Delphi exercise and applied at the Web-based reliability exercise ${ }^{14}$ were also used in the patient-based reliability exercises:

- Normal temporal artery: Pulsating, compressible artery with anechoic lumen surrounded by mid- to hyperechoic tissue. Using US equipment with high resolution, the intima-media complex (IMC) presents as a homogeneous, hypo-, or anechoic echo structure delineated by 2 parallel hyperechoic margins (double-line pattern) may be visible.

- Normal axillary artery: Pulsating, hardly compressible artery with anechoic lumen; the IMC presents as a homogeneous, hypoechoic, or anechoic echo structure delineated by 2 parallel hyperechoic margins (double-line pattern), which is surrounded by mid- to hyperechoic tissue.

- Halo sign: Homogeneous, hypoechoic wall thickening, well delineated toward the luminal side, visible both in longitudinal and transverse planes, most commonly concentric in transverse scans.

- Compression sign: The thickened arterial wall remains visible upon compression; the hypoechogenic vasculitic vessel wall thickening contrasts with the mid-echogenic to hyperechogenic surrounding tissue.

Figures explaining these definitions can be found in the article describing the Delphi process in more detail ${ }^{14}$ and in another review article ${ }^{20}$.

Statistical analysis. All sonographers (1-12) evaluated all study subjects (n $=6$ ) in 2 rounds, in a total of 8 anatomical positions (common temporal artery, parietal branch, frontal branch, and axillary artery), taking both sides of the body (right, left) into account. Intra- and interreader reliabilities were calculated using the kappa coefficient $(\kappa)$. Intrareader reliability was assessed by Cohen $\kappa$. Interreader reliability was studied by calculating the mean $\kappa$ on all pairs (i.e., Light $\kappa)^{21}$. Kappa coefficients and the corresponding $95 \% \mathrm{CI}$ were interpreted according to Landis and Koch: $\kappa$ values of $0-0.2$ were considered poor, 0.2-0.4 fair, 0.4-0.6 moderate, 0.6-0.8 good, and 0.8-1 excellent ${ }^{22}$. The percentage of observed agreement (i.e., percentage of observations that obtained the same score), prevalence of the observed lesions, and prevalence-adjusted bias-adjusted $\kappa$ (PABAK) were also calculated ${ }^{23,24}$. Analyses were performed using R Statistical Software (Foundation for Statistical Computing).

\section{RESULTS}

Preliminary meeting. The mean interrater agreement for the overall diagnosis of GCA was 0.73 in round 1 and 0.83 in round 2 . It was 0.79 in round 1 and 0.77 in round 2 for identifying vasculitis in the respective anatomical segments. The mean intrarater agreements were $0.82(0.50-1)$ for the overall diagnosis of GCA and 0.84 (range $0.58-1$ ) for identifying vasculitis in the respective anatomical segments.

The mean interrater reliabilities were fair to moderate for the overall diagnosis of GCA (Light $\kappa$ 0.29-0.51) and poor to fair for identifying vasculitis in the respective anatomical segments (Light $\kappa$ 0.02-0.46). Mean intrarater reliabilities were moderate (Cohen $\kappa$ 0.32-0.64).

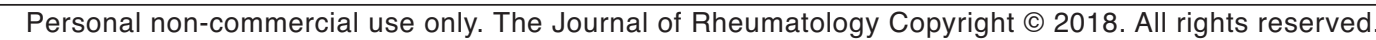


Table 1. Interrater reliability and agreement in the full exercise (Round 1).

\begin{tabular}{|c|c|c|c|c|}
\hline Variables & \multicolumn{3}{|c|}{ Prevalence, $\%$ Agreement } & $\begin{array}{l}\text { Mean } \\
\text { PABAK }\end{array}$ \\
\hline US positive for GCA & 61.1 & 0.88 & 0.76 & 0.77 \\
\hline \multicolumn{5}{|l|}{ Halo sign } \\
\hline $\begin{array}{l}\text { Iemporal arteries, all } \\
\text { segments }\end{array}$ & 31.3 & 0.77 & 0.47 & 0.55 \\
\hline \multicolumn{4}{|l|}{ Common superficial } & 0.55 \\
\hline Frontal branch & 31.2 & 0.77 & 0.46 & 0.54 \\
\hline Parietal branch & 27.8 & 0.78 & 0.46 & 0.56 \\
\hline Axillary arteries & 52.4 & 0.83 & 0.66 & 0.66 \\
\hline \multicolumn{5}{|l|}{ Compression sign } \\
\hline \multicolumn{5}{|l|}{ Temporal arteries, } \\
\hline $\begin{array}{l}\text { Common superficial } \\
\text { temporal artery }\end{array}$ & 35.4 & 0.78 & 0.51 & 0.57 \\
\hline Frontal branch & 33.3 & 0.75 & 0.44 & 0.49 \\
\hline Parietal branch & 29.2 & 0.80 & 0.53 & 0.60 \\
\hline
\end{tabular}

PABAK: prevalence-adjusted bias-adjusted kappa; GCA: giant cell arteritis; US: ultrasound.

Table 2. Interrater reliability and agreement in the full exercise (Round 2).

\begin{tabular}{|c|c|c|c|c|}
\hline Variables & $\begin{array}{c}\text { Mean } \\
\text { Prevalence, }\end{array}$ & $\begin{array}{l}\text { Mean } \\
\text { greement }\end{array}$ & Mean $\kappa$ & $\begin{array}{l}\text { Mean } \\
\text { PABAK }\end{array}$ \\
\hline US positive for GCA & 62.5 & 0.93 & 0.86 & 0.86 \\
\hline $\begin{array}{l}\text { Halo sign } \\
\text { Temporal arteries, }\end{array}$ & 333 & 088 & 0.60 & 065 \\
\hline $\begin{array}{l}\text { Common superficial } \\
\text { temporal artery }\end{array}$ & 41.0 & 0.86 & 0.71 & 0.72 \\
\hline Frontal branch & 31.3 & 0.79 & 0.50 & 0.58 \\
\hline Parietal branch & 27.8 & 0.82 & 0.54 & 0.65 \\
\hline Axillary arteries & 52.8 & 0.81 & 0.64 & 0.63 \\
\hline \multicolumn{5}{|l|}{ Compression sign } \\
\hline $\begin{array}{l}\text { Temporal arteries, } \\
\text { all segments }\end{array}$ & 33.8 & 0.83 & 0.60 & 0.65 \\
\hline $\begin{array}{l}\text { Common superficial } \\
\text { temporal artery }\end{array}$ & 38.2 & 0.83 & 0.63 & 0.65 \\
\hline Frontal branch & 34.0 & 0.81 & 0.57 & 0.62 \\
\hline Parietal branch & 29.2 & 0.84 & 0.60 & 0.68 \\
\hline
\end{tabular}

GCA: giant cell arteritis; PABAK: prevalence-adjusted bias-adjusted kappa; US: ultrasound.

The independent sonographer rated 21 of 36 temporal artery segments (58\%) as ambivalent because of minor pathology, such as very small halo size of about $<0.5 \mathrm{~mm}$ and incomplete compressibility in some subsegments because of chronic changes in longstanding disease (Figure 1). He considered 4 of 12 axillary arteries (33\%) ambivalent including both axillary arteries of 1 control with unusually pronounced arteriosclerosis showing heterogeneous and in part hyperechoic, irregularly delineated, eccentric vessel wall alteration with a diameter of up to $1.7 \mathrm{~mm}$. Only 3 experienced sonographers (> 300 scans) considered the findings in these patients non-GCA in both rounds. There were $65 \%$ of sonographers who felt that unfamiliarity with the equipment might have hampered their results of false-positive or negative diagnosis and of intrareader reliability.

Full meeting. The mean interrater agreement for the overall diagnosis of GCA was 0.88 in round 1 and 0.93 in round 2 . It was 0.78 (range $0.75-0.83$ ) in round 1 and 0.82 (range $0.79-0.86$ ) in round 2 for identifying vasculitis in the respective anatomical segments. The mean intrarater agreements were 0.96 (range $0.83-1$ ) for the overall diagnosis of GCA and 0.89 (range 0.58-1) for identifying vasculitis in the respective anatomical segments.

The interrater reliability was good to excellent. The mean Light $\kappa$ was 0.76 in round 1 and 0.86 in round 2 for the overall diagnosis of GCA. The mean PABAK was 0.77 and 0.86 in rounds 1 and 2, respectively. For identifying vasculitis in the respective anatomical segments, the reliability was moderate for the temporal arteries (mean $\kappa 0.46-0.53$, mean PABAK 0.49-0.66) in round 1, moderate to good in round 2 (mean $\kappa$ 0.5-0.71, mean PABAK 0.58-0.72), and moderate for the axillary arteries in both rounds (mean $\kappa$ 0.64-0.66). The intrareader reliability was excellent for the diagnosis of GCA (Cohen $\kappa$ 0.91, PABAK 0.92) and good (Cohen $\kappa$ $0.71-0.80$, PABAK $0.73-0.81$ ) for the respective anatomical segments.

The independent sonographer rated 14 of 36 temporal artery segments (39\%) and none of the 12 axillary arteries as ambivalent due to minor pathology because of chronic changes in longstanding disease. All sonographers agreed in both rounds that the controls had no GCA. Agreement was also $100 \%$ in both rounds for the diagnosis of GCA in 3 patients with GCA. Disagreement occurred only when 5/12 and 3/12 sonographers missed the diagnosis of GCA in rounds 1 and 2, respectively, in 1 obese patient with bilateral axillary artery vasculitis, very small residual artery lumen, pronounced collateral flow, and normal temporal arteries (Figure 2).

In both exercises, reliabilities did not significantly differ whether halo sign or compression sign was evaluated. The detailed results are shown in Table 1, Table 2, and Table 3.

\section{DISCUSSION}

The inter- and intrarater reliabilities for performing US of temporal and axillary arteries in patients with GCA and controls were good to excellent for the diagnosis of GCA with experienced sonographers who were familiar with the US equipment.

Better reliabilities attained in the full exercise compared to the preliminary exercise could be explained by the following:

(1) Lack of sonographer training on the US equipment and its settings in the preliminary exercise. Only $42 \%$ of sonographers in the preliminary exercise and $50 \%$ in the full exercise were using similar equipment in their institutions.

Personal non-commercial use only. The Journal of Rheumatology Copyright @ 2018 . All rights reserved. 
Table 3. Intrarater reliability and agreement in the full exercise.

\begin{tabular}{|c|c|c|c|c|c|c|c|}
\hline Variables & $\begin{array}{c}\text { Mean } \\
\text { Prevalence, \% }\end{array}$ & $\begin{array}{c}\text { Mean } \\
\text { Agreement }\end{array}$ & Mean $\kappa$ & $\begin{array}{c}\text { Mean } \\
\text { PABAK }\end{array}$ & $\begin{array}{c}\text { Range of } \\
\text { Agreement }\end{array}$ & Range, $\kappa$ & $\begin{array}{l}\text { Range, } \\
\text { PABAK }\end{array}$ \\
\hline US positive for GCA & 61.8 & 0.96 & 0.91 & 0.92 & $0.83-1$ & $0.57-1$ & $0.7-1$ \\
\hline Temporal arteries, all segments & 32.3 & 0.88 & 0.71 & 0.76 & $0.75-1$ & $0.31-1$ & $0.5-1$ \\
\hline Common superficial temporal artery & 37.9 & 0.87 & 0.71 & 0.73 & $0.67-1$ & $0.25-1$ & $0.3-1$ \\
\hline Frontal branch & 31.2 & 0.89 & 0.73 & 0.77 & $0.67-1$ & $0.27-1$ & $0.3-1$ \\
\hline \multicolumn{8}{|l|}{ Compression sign } \\
\hline Temporal arteries, all segments & 33.2 & 0.89 & 0.73 & 0.78 & $0.75-1$ & $0.34-1$ & $0.5-1$ \\
\hline Common superficial temporal artery & 36.8 & 0.89 & 0.75 & 0.77 & $0.67-1$ & $0.25-1$ & $0.3-1$ \\
\hline Frontal branch & 33.7 & 0.88 & 0.74 & 0.75 & $0.58-1$ & $0.17-1$ & $0.2-1$ \\
\hline Parietal branch & 29.2 & 0.89 & 0.72 & 0.77 & $0.67-1$ & $0.25-1$ & $0.3-1$ \\
\hline
\end{tabular}

GCA: giant cell arteritis; PABAK: prevalence-adjusted bias-adjusted kappa; US: ultrasound.

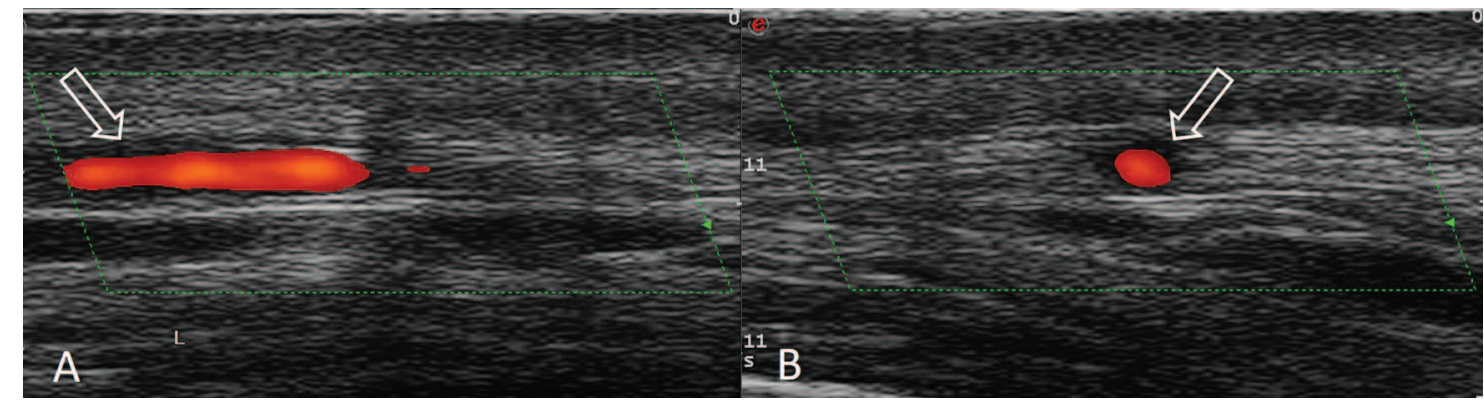

Figure 1. Small segmental, only slightly hypoechoic halo of a temporal artery branch in a patient of the full exercise with longstanding GCA. A. Longitudinal view. B. Transverse view. GCA: giant cell arteritis.
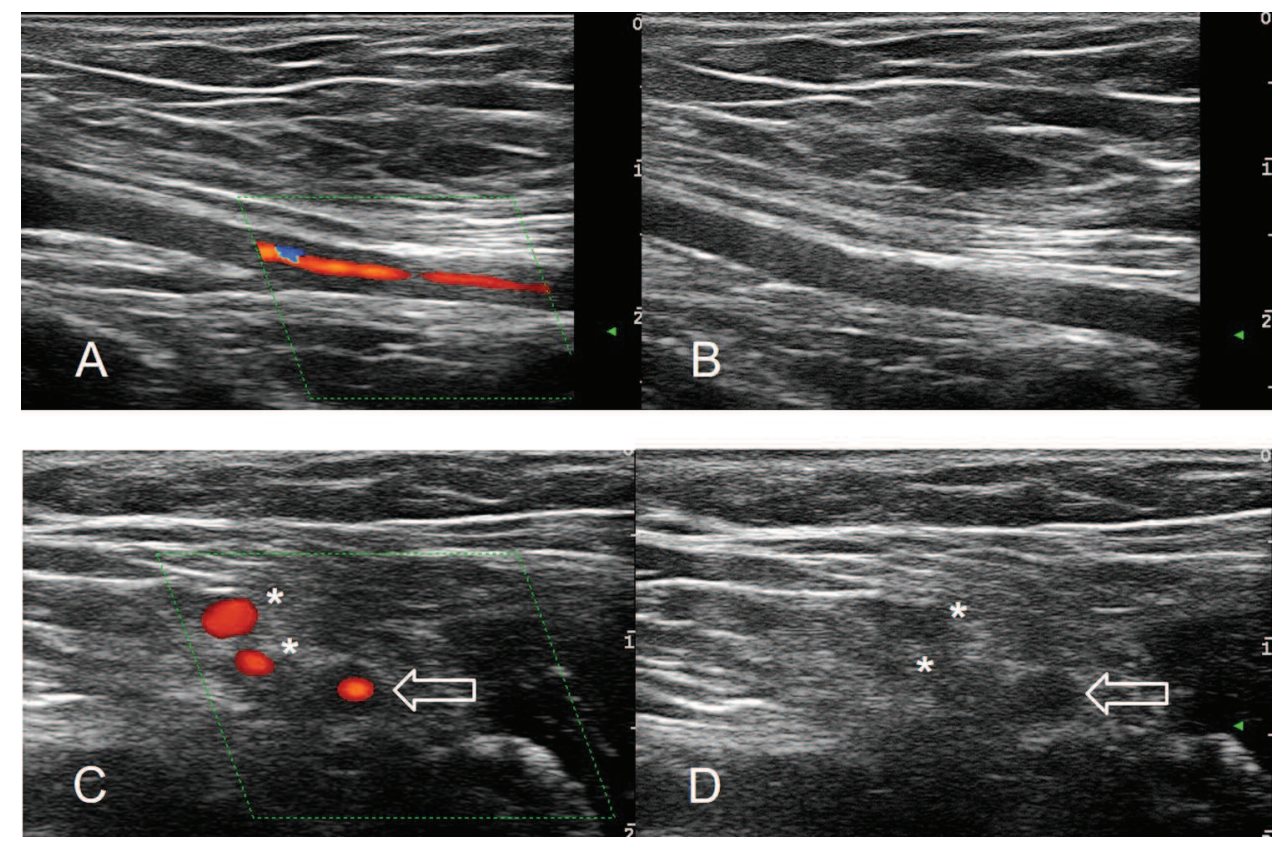

Figure 2. Halo sign of an axillary artery of a patient with GCA in the full exercise in longitudinal (A, B) and transverse $(C, D)$ views. It is only visible when applying color Doppler $(A, C)$. In the transverse views, collateral vessels without halo sign $(*)$ appear larger than the lumen of the affected axillary (arrows). GCA: giant cell arteritis. 
Even if a sonographer is familiar with a certain type of machine, experience with the settings is important as these may considerably influence the appearance of the US images. (2) Only $58 \%$ of sonographers in the preliminary exercise had performed > 300 examinations in suspected GCA compared to $92 \%$ in the full exercise. The European Federation of Societies for Ultrasound in Medicine and Biology minimum training requirements for rheumatologists performing musculoskeletal US demand a minimum of 300 US examinations for achieving level I competency ${ }^{25}$. Our current study suggests that this requirement may also apply for temporal and axillary artery US in suspected GCA.

(3) More time was provided for each examination in the full exercise because $67 \%$ of sonographers of the preliminary exercise said they felt that time restrictions had hampered the results. An examination time of 15-20 min appears to be optimal for examining temporal and axillary arteries in suspected GCA.

(4) The time frame when performing US is important for image interpretation. In patients with untreated GCA, the pathology is much more pronounced than in patients with longstanding, treated disease. The real-time patient-based reliability exercises, according to an OMERACT algorithm, are faced with this shortcoming, because it is impossible to obtain patients with untreated GCA for these exercises. The disease was more longstanding and pathologies were subtler in the preliminary exercise, with $52 \%$ of examined anatomical segments showing ambivalent findings compared to $29 \%$ in the full exercise. The sensitivity of temporal artery US decreases rapidly with glucocorticoid treatment. In 1 study, the sensitivity compared to the final clinical diagnosis dropped from $88 \%$ in patients who had been untreated or who had received glucocorticoids for not longer than 1 day, to $50 \%$ in patients who had been treated for 2 days or longer ${ }^{26}$. Another study, however, found that a residual halo sign may persist for 8 weeks in half of the patients ${ }^{27}$. In axillary arteries, US pathology may remain longer, for months and years, but it also decreases over time ${ }^{7}$. Nevertheless, as halo size decreases and halo echogenicity increases with treatment, it is more difficult to differentiate normal from abnormal findings in treated established GCA. This is probably also the case for histology because giant cells do not persist longer than 6 months ${ }^{28}$. Arteriosclerosis may be a potential confounder in the mainly elderly GCA population. It is, however, far less common in the temporal and axillary arteries than in the carotid and femoral arteries.

Few studies have yet assessed real-time patient-based reliabilities for US in suspected GCA. As for other indications and other imaging methods, reliability was higher when investigated for only 2 sonographers from the same institution. Agreement of 2 sonographers examining temporal arteries for halo sign, stenosis, and occlusions was $95 \%$ for the diagnosis of GCA in 1 study $^{2}$. In another study, 2 sonographers evaluating the compression sign of temporal arteries disagreed only in 1 of 60 patients ${ }^{29}$. A single study with multiple sonographers from Spain found excellent reliability with a $\kappa$ value of 0.85 for interreader reliability and of 0.95 for intrareader reliability after a training workshop ${ }^{30}$. The reliability in our study may be lower probably because of a tighter protocol.

Our study has limitations. The reliability may depend on the severity of the pathologic findings. Because all patients were receiving glucocorticoid treatment, reliability may have been impaired by ambivalent pathology. The repetition of the examination sequence on the same day may have led to overestimation of intrareader reliability. Although similar US equipment was used, even machines of the same type may exhibit different image features. Our study was performed with current high-quality modern $6-18 \mathrm{MHz}$ probes. Probes for examining temporal arteries should provide frequencies of $\geq 15 \mathrm{MHz}^{31}$. Probes with frequencies $>20 \mathrm{MHz}$ will further increase resolution and allow reliable measurement of the IMC of temporal arteries ${ }^{32}$. Very few of the sonographers participating in our study are using these probes. Further, IMC measurement of axillary arteries could have a role in future US protocols in suspected GCA.

These exercises following the OMERACT Ultrasound Group guidelines show that the OMERACT-derived definitions of halo and compression signs of temporal and axillary arteries are applicable in recent-onset GCA with excellent inter- and intrarater reliabilities for the diagnosis of GCA if sonographers are experienced, are provided sufficient time for examination, and are familiar with the US equipment, high frequency probes $>15 \mathrm{MHz}$, and settings.

\section{ACKNOWLEDGMENT}

The authors are indebted to the patients for their participation in the study. We also thank Katerina Achilleos and Kenny Schlüter, who helped organize the workshops in Southend and Berlin, respectively.

\section{REFERENCES}

1. Muratore F, Pipitone N, Salvarani C, Schmidt WA. Imaging of vasculitis: state of the art. Best Pract Res Clin Rheumatol 2016;30:688-706.

2. Schmidt WA, Kraft HE, Vorpahl K, Völker L, Gromnica-Ihle EJ. Color duplex ultrasonography in the diagnosis of temporal arteritis. N Engl J Med 1997;337:1336-42.

3. Aschwanden M, Daikeler T, Kesten F, Baldi T, Benz D, Tyndall A, et al. Temporal artery compression sign - a novel ultrasound finding for the diagnosis of giant cell arteritis. Ultraschall Med 2013; 34:47-50.

4. Diamantopoulos AP, Haugeberg G, Lindland A, Myklebust G. The fast-track ultrasound clinic for early diagnosis of giant cell arteritis significantly reduces permanent visual impairment: towards a more effective strategy to improve clinical outcome in giant cell arteritis? Rheumatology 2016;55:66-70.

5. Patil P, Williams M, Maw WW, Achilleos K, Elsideeg S, Dejaco C, et al. Fast track pathway reduces sight loss in giant cell arteritis: results of a longitudinal observational cohort study. Clin Exp Rheumatol 2015;33:S-103-6.

6. Luqmani R, Lee E, Singh S, Gillett M, Schmidt WA, Bradburn M, et al. The role of ultrasound compared to biopsy of temporal arteries in the diagnosis and treatment of giant cell arteritis (TABUL): a diagnostic accuracy and cost-effectiveness study. Health Technol

Personal non-commercial use only. The Journal of Rheumatology Copyright @ 2018 . All rights reserved. 
Assess 2016;20:1-238.

7. Schmidt WA, Seifert A, Gromnica-Ihle E, Krause A, Natusch A Ultrasound of proximal upper extremity arteries to increase the diagnostic yield in large-vessel giant cell arteritis. Rheumatology 2008;47:96-101.

8. Karassa FB, Matsagas MI, Schmidt WA, Ioannidis JP. Meta-analysis: test performance of ultrasonography for giant-cell arteritis. Ann Intern Med 2005;142:359-69.

9. Ball EL, Walsh SR, Tang TY, Gohil R, Clarke JM. Role of ultrasonography in the diagnosis of temporal arteritis. Br J Surg 2010;97:1765-71.

10. Arida A, Kyprianou M, Kanakis M, Sfikakis PP. The diagnostic value of ultrasonography-derived edema of the temporal artery wall in giant cell arteritis: a second meta-analysis. BMC Musculoskelet Disord 2010;11:44.

11. Duftner C, Dejaco C, Sepriano A, Falzon L, Schmidt WA, Ramiro $\mathrm{S}$. Imaging in diagnosis, outcome prediction and monitoring of large vessel vasculitis: A systematic literature review and meta-analysis informing the EULAR recommendations. RMD Open 2018;4:e000612.

12. Tuckwell K, Collinson N, Dimonaco S, Klearman M, Blockmans D, Brouwer E, et al; GiACTA Investigators. Newly diagnosed vs. relapsing giant cell arteritis: Baseline data from the GiACTA trial. Semin Arthritis Rheum 2017;46:657-64.

13. Dejaco C, Ramiro S, Duftner C, Besson FL, Bley TA, Blockmans D, et al. EULAR recommendations for the use of imaging in large vessel vasculitis in clinical practice. Ann Rheum Dis 2018; 77:636-43.

14. Chrysidis S, Duftner C, Dejaco C, Schäfer VS, Ramiro S, Carrera $\mathrm{G}$, et al. Definitions and reliability assessment of elementary ultrasound lesions in giant cell arteritis: a study from the OMERACT Large Vessel Vasculitis Ultrasound Working Group. RMD Open 2018;4: e000598.

15. Terslev L, Gutierrez M, Christensen R, Balint PV, Bruyn GA, Delle Sedie A, et al; OMERACT US Gout Task Force. Assessing elementary lesions in gout by ultrasound: results of an OMERACT patient-based agreement and reliability exercise. J Rheumatol 2015;42:2149-54

16. Terslev L, Naredo E, Aegerter P, Wakefield RJ, Backhaus M, Balint $P$, et al. Scoring ultrasound synovitis in rheumatoid arthritis: a EULAR-OMERACT ultrasound taskforce-Part 2: reliability and application to multiple joints of a standardised consensus-based scoring system. RMD Open 2017;3:e000427.

17. Filippou G, Scire CA, Damjanov N, Adinolfi A, Carrara G, Picerno $\mathrm{V}$, et al. Definition and reliability assessment of elementary ultrasonographic findings in calcium pyrophosphate deposition disease: a study by the OMERACT Calcium Pyrophosphate Deposition Disease Ultrasound Subtask Force. J Rheumatol 2017;44:1744-9.
18. Christensen R, Bliddal H, Henriksen M. Enhancing the reporting and transparency of rheumatology research: a guide to reporting guidelines. Arthritis Res Ther 2013;15:109.

19. Kottner J, Gajewski BJ, Streiner DL. Guidelines for Reporting Reliability and Agreement Studies (GRRAS). Int J Nurs Stud 2011;48:659-60.

20. Schmidt WA. Ultrasound in the diagnosis and management of giant cell arteritis. Rheumatology 2018;57:ii22-31.

21. Light RJ. Measures of response agreement for qualitative data: some generalizations and alternatives. Psychol Bull 1971;76:365-77.

22. Landis JR, Koch GG. The measurement of observer agreement for categorical data. Biometrics 1977;33:159-74.

23. Byrt T, Bishop J, Carlin JB. Bias, prevalence and kappa. J Clin Epidemiol 1993;46:423-9.

24. Gisev N, Bell JS, Chen TF. Interrater agreement and interrater reliability: key concepts, approaches, and applications. Res Social Adm Pharm 2013;9:330-8.

25. Terslev L, Hammer HB, Torp-Pedersen S, Szkudlarek M, Iagnocco A, D'Agostino MA, et al. EFSUMB minimum training requirements for rheumatologists performing musculoskeletal ultrasound. Ultraschall Med 2013;34:475-7.

26. Hauenstein C, Reinhard M, Geiger J, Markl M, Hetzel A, Treszl A, et al. Effects of early corticosteroid treatment on magnetic resonance imaging and ultrasonography findings in giant cell arteritis. Rheumatology 2012;51:1999-2003.

27. De Miguel E, Roxo A, Castillo C, Peiteado D, Villalba A, Martin-Mola E. The utility and sensitivity of colour Doppler ultrasound in monitoring changes in giant cell arteritis. Clin Exp Rheumatol 2012;30:S34-8.

28. Maleszewski JJ, Younge BR, Fritzlen JT, Hunder GG, Goronzy JJ, Warrington KJ, et al. Clinical and pathological evolution of giant cell arteritis: a prospective study of follow-up temporal artery biopsies in 40 treated patients. Mod Pathol 2017;30:788-96.

29. Aschwanden M, Imfeld S, Staub D, Baldi T, Walker UA, Berger CT, et al. The ultrasound compression sign to diagnose temporal giant cell arteritis shows an excellent interobserver agreement. Clin Exp Rheumatol 2015;33:S113-5.

30. De Miguel E, Castillo C, Rodriguez A, De Agustin JJ; Working Group Ultrasound Giant Cell Arteritis. Learning and reliability of colour Doppler ultrasound in giant cell arteritis. Clin Exp Rheumatol 2012;27:S53-8.

31. Monti S, Floris A, Ponte C, Schmidt WA, Diamantopoulos AP, Pereira $\mathrm{C}$, et al. The use of ultrasound to assess giant cell arteritis: review of the current evidence and practical guide for the rheumatologist. Rheumatology 2017;57:227-35.

32. Schäfer VS, Juche A, Ramiro S, Krause A, Schmidt WA. Ultrasound cut-off values for intima-media thickness of temporal, facial and axillary arteries in giant cell arteritis. Rheumatology 2017; $56: 1479-83$ 